\title{
SAFER than SAFE: China Club as a model of a positive after-school initiative
}

Claire Cassidy, University of Strathclyde, Scotland

Ninetta Santoro, Swinburne University of Technology, Australia

\begin{abstract}
This article reports on a study that investigated the effectiveness of one out-of-school activity: 'China Club'. China Club, an initiative of Scotland's National Centre for Languages and the Confucius Institute for Scotland's Schools was established with the central aim of teaching Mandarin language and Chinese culture to young people from a secondary school in the West of Scotland. The article explores the success of China Club against criteria established by Durlak and Weissberg (2007) to ascertain programme success; how well the programme is: sequenced; active; focused; explicit (SAFE). We took an ethnographic case study approach, complemented by interviews with pupils, teachers and those leading the programme to investigate the effectiveness of China Club. We argue that the China Club has all the elements of a SAFE programme. Further, we suggest that more than these four factors are necessary if an out-of-school initiative is to move successfully beyond academic skills development to the personal and social growth of the individuals involved. We conclude that initiatives must also foster and include the opportunity for the development of effective relationships $(\mathrm{R})$.
\end{abstract}

Keywords: after-school programmes; out-of-school activities; relationships; evaluative framework

\section{Introduction}


Schools increasingly provide learning opportunities for their pupils that extend beyond the school day and normal school hours. This may be due to the ever-growing pressures on school curricula, the drive for teachers to ensure the academic success of pupils, and in some national contexts, the rise in importance of national tests and publicly available school league tables. Out-of-school learning opportunities often align with in-school learning and are designed to support pupils' academic learning. They are held on school premises and/or are run by teachers that the pupils work with on a day-to-day basis (Bennett, 2015). At other times, programmes are not conducted on school premises, and are not taught by teachers. Nonetheless, they often aim to extend the formal school curriculum, providing pupils with additional academic support. At times, programmes are designed to change the behaviours of young people who are perceived as problematic (Damon, 2004; Hamilton, 2015).

Durlak, Weissberg and Pachan (2010) suggest that the move towards using out-of-school activities for the development of academic skills emerged from out-of-school programmes that mainly focus on the development of "personal and social growth" (p. 295). However, with an increasing focus on the development of measurable skills and outcomes in schools (Durlak \& Weissberg, 2007), many out-of-school programmes are assessed and designed in accordance with the benefits they bring to young people's academic learning and to their acquisition of a set of discrete or inter-related skills (Pastor \& Vásquez, 2011). However, there is also increasing recognition that social development might be enhanced through such programmes, thereby leading to an alternative, non-academic focus. In the Positive Youth Development (PYD) movement, the focus is "an ecological, asset-based approach that promotes healthy human development through supportive environments and community connections" (Bradshaw, Brown \& Hamilton, 2008, p. 209). Through such an approach, several aspects of young people's development are addressed (Hamilton, 2014). Often this 
includes skills development. Durlak, et al. (2010) describe young people developing and applying "new skills and talents" (p. 295) in the domain of personal and social skills. Opportunities must be given to ensure that young people can develop these skills (Durlak \& Weissberg, 2007). However, after-school initiatives seem destined to be programmatic, and focus on training young people to be 'particular kinds of people'. Indeed, much literature has discussed training in this regard (see, for example, Durlak \& Weissberg, 2007; Cobbett, 2016; Idsoe, 2016). Even the literature relating to PYD often reports on programmes designed to address specific behaviour problems or the development of character (see, for example, Catalano, Berglund, Ryan, Lonczak \& Hawkins, 2004; Damon 2004; Bradshaw et al., 2008).

Despite the predominance of out-of-school programmes that develop academic skills and extend school curricula, there are other initiatives that do not connect to formal school curricula and are not necessarily about improving pupils' academic grades. Some out-ofschool programmes have been established with a clear political agenda, such as the need to keep children occupied, or away from danger after school. These initiatives are seen as an important step in addressing increased crime rates, providing opportunities to promote prosocial behaviour, and supporting working parents (Bradshaw et al., 2008; Catalano et al., 2004; Hirsch, Mekinda \& Stawicki, 2010; McDaniel \& Yarbrough, 2016; Rhodes, 2004). Furthermore, while out-of-school sports programmes will train young people to develop and apply particular skills, these are intended to develop their abilities in ways that support their engagement with, and enjoyment of the activity such as swimming, horse riding, football or athletics. Other initiatives may support children to grow their social networks either with their peers, with adults, members of their wider community, or beyond (Fredricks \& Simpkins, 2013; Santoro, Cassidy \& MacDonald, 2018). Some programmes are established 
to provide opportunities for young people to receive mentoring (Hamilton, 2014). The mentoring relationship is often designed to build confidence in the young person being mentored, provide a stable adult or role model for them, or support the young person in experiencing new things (McDade, 2005; McDaniel \& Yarbrough, 2016; Rhodes, 2004).

Whatever the goal of the out-of-school activity, due consideration must be given to the young people's social contexts and what they might find relevant and potentially useful (Simpkins, Riggs, Ngo, Ettekal \& Okamoto, 2017). Consequently, the purpose of the activities will determine whether the initiatives are called "after-school programmes", "extra-curricular activities" or "clubs" (Santoro et al., 2018).

This article reports on a study that investigated the effectiveness of one out-of-school programme: 'China Club', an initiative of Scotland's National Centre for Languages (SCILT) and the Confucius Institute for Scotland's Schools (CISS). The programme was hosted at a large Scottish University and was funded by Hanban. Hanban is the headquarters of Confucius Institutes, the non-profit Chinese "public institution affiliated with the Chinese Ministry of Education [that is] committed to providing Chinese language and cultural teaching resources and services worldwide" (http://english.hanban.org/node 7719.htm).

China Club had, as its central aim, the teaching and promotion of Mandarin language and Chinese culture to young people from a secondary school in the West of Scotland. While the focus of China Club sat well within the frame of the Scottish Government's 1+2 languages agenda, where all pupils in Scotland are given opportunities to learn two languages in addition to their home language during their time at school (Scottish Government, 2012), China Club was not a school activity. It was not aligned with the formal school curriculum or 
designed explicitly to increase pupils' academic results. There were no formal assessments in China Club. The sessions were planned and run by teachers from China who had applied to work with SCILT/CISS for a period of a year. The sessions were not taught by teachers from the pupils' school. While some of the activities were highly structured, the sessions were generally intended to be informal. SCILT/CISS tried to make this clear in the naming of the initiative, with the term 'club' being more commonly associated with informal, fun activities. The 'club', therefore, was not an intervention to address a particular need in the young people's lives or to address certain elements of their behaviour, but was an enrichment programme created to provide opportunities that were not available within their school context.

\section{China Club}

At the time of writing, two groups of young people, China Club 1 and China Club 2, had joined China Club. China Club 1 was established nine months prior to the China Club 2. The young people were aged between twelve and fourteen. Participants learned some basic Mandarin vocabulary, pinyin and characters. They also engaged in a variety of cultural activities such as paper-cutting, making New Year decorations and visiting Chinese restaurants and supermarkets in the city. China Club 1 participants also had the experience of visiting China for a sponsored two-week trip. During their time in China, they were paired with a Chinese peer who would accompany them to school. The pupils also visited the home of their Chinese partner.

The sessions were held at the university after the school day had finished. When there were occasional difficulties with transport to the university the sessions were held at the school. 
Although it was not a main aim of China Club, it was hoped that using the university space would give the young people from one of the most economically and socially deprived areas in Scotland, opportunities to move beyond their immediate local area and raise their aspirations to later undertake university study. In this respect, China Club was an amalgam of approaches to out-of-school programmes that bridge formal and informal contexts and the development of academic and social skills.

This article explores the success of China Club using Durlak and Weissberg's (2007) SAFE (sequenced, active, focused, explicit) model that advances the notion of the four key features deemed as crucial in the successful social and personal development of young people. The effectiveness of out-of-school activities can be gauged against many features. These features may include: the development of character and moral identity; opportunities for prosocial involvement; programme implementation; the fostering of a positive belief in the future; the promotion of spirituality; and the extent to which theory and practice are linked (see, for example, Catalano et al 2004; Damon, 2004; Hamilton, 2015). The Durlak and Weissberg (2007) framework is well-established in the literature. It is concise and well-suited to monitor the effectiveness of an initiative such as China Club, paying particular attention to how well it is sequenced, active, focused, and explicit (SAFE). The research team therefore decided that this pre-existing and trustworthy framework would prove effective.

In what follows, we discuss the framework used to ascertain the effectiveness of the China Club, describe the research methodology of the study, and present our data and findings to show that the China Club has all the elements of a SAFE programme. Further, we suggest that more than these four factors are necessary if an out-of-school initiative is to move successfully beyond academic skills development to the personal and social growth of the 
individuals involved. We claim that initiatives must foster and include the opportunity for the development of effective relationships $(\mathrm{R})$ if they are to be holistic.

Drawing on literature that claims that there should be collaboration between those in the field, practitioners in the out-of-school context, and researchers in universities (Hamilton 2015), the research findings in this article are intended to inform future practice, both in the context discussed, and more widely.

\section{The 'SAFE' Framework}

Durlak and Weissberg (2007) advocate a SAFE approach to skills development programmes for young people. This requires that the programme or series of activities that lead to skills development are "sequential, active, focused and explicit" (Durlak \& Weissberg, p. 4). The four criteria of SAFE can be split into two distinct elements. The first pertains to the process, where there is a "sequenced set of activities to achieve skill objectives" (Durlak \& Weissberg, p. 5) (sequenced), and where learning that promotes active engagement is employed (active). The second element relates to the content of the initiative. The content should have a focus, at least in part, on the development of social or personal skills (focus) and there should be a clear "targeting of specific personal or social skills (explicit)" (Durlak \& Weissberg, p. 5). Durlak and Weissberg go on to claim that,

It is important to stress that only those programs that followed these four evidencebased training approaches in their program components devoted to skill development produced significant changes in any outcomes. In other words, it is the combination of both training process (i.e., sequential and active) and program content (i.e., focused and explicit) that leads to positive results (Durlak \& Weissberg, p. 6). 
We consider use of the term 'training' to be problematic. It suggests drilling or a scheme of rewards and sanctions, somewhat akin to a behaviourist approach (Kohn, 1999). The notion of training children and young people does not sit easily with the idea of enhancement or growth in the sense of promoting a flourishing life, one that constitutes more than social conditioning. The China Club was established to teach the young people some Mandarin language and about facets of Chinese culture, but the original intention was not to train the young people in social, academic or personal skills, though it was hoped that it would support the participants' confidence, global awareness and cultural knowledge.

Leaving aside the objections to the term training, the notion of SAFE is useful. It enables us to see the extent to which the China Club met the requirements of a SAFE programme: that SCILT/CISS was "explicit about what they wish to achieve, use activities that are coordinated and sequenced to achieve their purpose, and require active involvement on the part of participants" (Durlak \& Weissberg, 2007, p. 6). Indeed, writing some years following the initial report, Durlak, Weissberg and Pachan (2010) in their meta-analysis of after-school programmes, stand by the SAFE formula. It should be noted that the first element, that of sequencing, was determined by SCILT/CISS, the adults running the initiative. According to Granger (2008), the remaining three - active, focus, explicit - should be more flexible and allow young people choice. He suggests that "policymakers should encourage the sort of student-centered, active, project-based learning that plays to the comparative strengths of the after-school hours" (p. 16).

\section{Researching China Club: Methods}


China Club was an initiative offered to children in a school located in an area within 5 percent of the most deprived areas in Scotland (Scottish Government, 2016). Given the particularly low socio-economic status experienced by residents in the area, they commonly experience high unemployment, low life expectancy, poor physical and mental health and poor levels of formal education. Housing conditions are often poor and public transport is limited in the area.

The initial approach to SCILT to run China Club had come from the school because, according to the SCILT Director, the school was unable to deliver the languages curriculum as comprehensively as they wanted due to staff shortfalls. As the Hanban teachers had joined SCILT and had opportunities to work with the Confucius Institute for a year, SCILT staff thought the China Club would provide opportunities for the Hanban teachers to gain skills in a local context and also support the school in their endeavours to provide Mandarin language education.

In total, twenty-one young people, aged between thirteen and sixteen, participated in China Club 1 and China Club 2. There were eight male participants and thirteen females. The study also included two Hanban teachers, two school teachers, the Director of SCILT and one of SCILT's administrative team who had responsibility for co-ordinating China Club. Informed, written consent to participate in the research study was provided by all participants and their parents, as appropriate.

An ethnographic case study approach was adopted for the study. Ethnographic research techniques are well established and widely recognised for their success within educational settings because they produce in-depth and rich contextual data (Hammersley, 2006, 2016; 
Cohen, Manion, \& Morrison, 2011). A traditional ethnography prioritises a holistic investigation and requires the researcher to become immersed in the culture being studied and to engage with individuals or groups over a very lengthy period of time, sometimes years. However, an ethnographic case study is conducted over a shorter time span. It can sometimes be described as a mini ethnography or a focused ethnography (White, 2009) because it "bounds the research in time and space" (Fusch, Fusch \& Ness, 2017, p. 926). Furthermore, while a traditional ethnography relies on observation notes and journals, an ethnographic case study also includes semi-structured interviews, a data collection method more commonly associated with case study. The flexibility and practicality offered by an ethnographic case study approach was an attractive option for researching the China Club.

In the study reported here, data were collected over seven months in 2015-2016 by direct observations, observation logs and semi-structured, in-depth interviews. The school staff were interviewed individually, while the young people participated in focus group interviews. The young people were interviewed as a group because it was not possible for them to have time out of class during the school day, so an hour-long session was scheduled to be held after school. Staff, on the other hand, had periods in the school when they were not teaching but this was not at the same time, so this allowed for hour-long interviews during the day. The interviews were audio-recorded and later transcribed for analysis.

Over seven months, the young people and the Hanban teachers were observed 20 times engaging in their normal China Club activities during the weekly two-hour sessions. The researchers sat in the classroom, sometimes remaining unobtrusive and at other times they actively participated in the language learning sessions by saying the new vocabulary aloud with the class or participating in some of the games. Thus, they alternated between being 
insiders and outsiders and participant and non-participant observers. This meant that they were known to the young people so that when it was time to discuss China Club in the interviews the young people felt more relaxed and comfortable. The researchers used the same observation templates to record the sessions and one to three of them were present at each session. They made notes about the pedagogical approaches used by the teachers. They also recorded the pupils' responses to tasks in terms of their engagement and participation with the tasks. Pupil-pupil interactions and the teacher-pupil interactions were also recorded. Pupil-pupil interactions and teacher-pupil interactions were simply the types of interaction they had, while engagement and participation reflected the level or enthusiasm with which the young people were engaged in the activity. The researchers' observation logs were collated by one of the team following each session.

Eight of the young people participated in a focus group discussion where they talked about learning Mandarin and about elements of Chinese culture. They also spoke about the nature of the lessons, the role of the Hanban teacher and the interactions they had with one another and with the teacher. As the young people from China Club 1 had visited China as part of the programme, they also discussed their experiences in preparing for the trip, and those they had while in China. They were invited to talk about what they found challenging or enjoyable about the trip and what they had learned about China as a consequence of their visit. One of the school teachers recruited the focus group volunteers and provided space in the school for the meeting. While all of the young people were invited to participate in focus group discussions, some were unable to attend because they had other commitments at the time. The interview lasted approximately fifty minutes and was audio-recorded and later transcribed. 
Although the voluntary nature of participation in the interview may lead to the suggestion that only those who were positive about the Club would attend, all of the young people attended and presented at a conference, at which the research team were present. They unanimously presented positive experiences of China Club. None of the young people articulated suggestions for the improvement of China Club.

Two teachers from the secondary school and the two Hanban teachers, the Director of SCILT and a Project Officer from SCILT participated in semi-structured interviews. One of the Hanban teachers had accompanied the young people to China. The interviews provided data on the young people's Mandarin learning, their engagement with the elements of Chinese culture that had been taught, and whether they considered China Club to be successful in achieving its aims. The Hanban teachers were also asked about the professional challenges they experienced in teaching China Club. The SCILT Director's interview focused on the rationale for establishing China Club and the extent to which she thought it was fulfilling its aims. The one-to-one interviews lasted approximately 40-60 minutes and were conducted at the University, or in the case of the teachers, at the school. All interviews were audiorecorded and subsequently transcribed.

Jeffrey (2008) states, when ethnographic methods are used, data collection and analysis actually occurs simultaneously. The research team made decisions about who and what to observe when they entered the research setting each week. This resulted in early observations influencing the subsequent data collected in addition to allowing us to refine interview questions on the basis of these preliminary understandings. When all data were collected, a process of thematic analysis was undertaken. It enabled us to understand "the complexities of 
meaning within a textual data set" (Guest, MacQueen \& Namey, 2011, p. 11) and allowed for the interpretation of multiple realities.

Individually and independently, the researchers read the data, re-read it and identified patterns in the data by employing a process of open coding. The collation of the codes made it possible to identify a "central organising concept" (Braun \& Clarke, 2013, p. 224) or a theme of "substantive significance" (Patton, 2002, p. 467). The team then compared and contrasted the themes across the data, looked for differences, similarities, contradictions, tensions and complexities, and evaluated the success of China Club against Durlak and Weissberg's (2007) SAFE (sequenced, active, focused, explicit) characteristics. While Durlak and Weissberg focused specifically on the development of social and personal skills development, our data revealed the importance of relationships in creating a positive afterschool experience for young people. Elsewhere, we have presented data about the young people's viewpoints about relationships built through China Club, specifically in relation to bonding and bridging capital (Santoro, Cassidy \& MacDonald., 2018).

As is the case with ethnographic methods whereby the researcher is the primary instrument of data collection, researcher reflexivity was central to this research, including during the data analysis. Santoro and Smyth (2010) note that data do not "exist in some predefined form, ripe for the picking” (p. 494); researcher subjectivity means qualitative researchers actually produce and generate data through the choices they make. Therefore, we were conscious of the ongoing need to interrogate our biases and positioning as insiders and outsiders to the research context at different moments in time. This meant we individually reflected on our notes and compared our interpretation of the data against our prior understanding of the 
context as either insiders or outsiders. We then came together to collectively repeat this process of interrogation.

\section{Results}

\section{Sequenced}

An initiative or programme might be considered sequenced if "it used a sequential set of activities to achieve its objective... often achieved by using or adapting an established curriculum" (Granger, 2008, p. 11). As noted previously, while China Club was associated with the school by virtue of the participants coming from the one location, the content and structure of China Club was independent of the school. SCILT's Director was clear:

We didn't want it to be a class; we wanted it to be really engaging, we wanted them to have a sense of unity and togetherness that you would get with a club... we didn't want there to be an idea of compulsion or scholarisation about it. (SCILT Director, interview, June 7, 2016).

The two Hanban teachers had responsibility for the planning of the Club's activities. The Hanban teacher who had worked with China Club 1 initially provided support for the teacher who joined SCILT the following year to lead China Club 2. This means that China Club 2's programme of activities was dictated in some part by what had taken place in China Club 1 because resources were shared. That said, the Hanban teachers were often responsive to the young people's interests. Hirsch et al. (2010) are clear that the planning of activities is of secondary importance to the implementation of them. McDaniel and Yarbrough (2016) similarly advocate the need for negotiated activities that are grounded in common interests 
and offer participants an element of choice. This was somewhat challenging for the Hanban teachers as the young people's knowledge of China and Chinese culture was very limited at the start of the initiative. One participant had heard of the Great Wall, a couple knew about the importance of pandas and others knew something about Chinese food, but this knowledge of food was limited to what they had encountered in the local take-away restaurant, with some of the group never having tasted Chinese food at all. This meant that sequencing activities that were led by the young people's ideas were more challenging, so the Hanban teachers had to plan based on the young people's responses. However, there was a clear sequence or timing to some of the activities, for example, visiting the Chinese supermarket preceded the cookery lesson, and lantern making took place to coincide with Chinese New Year. Other activities, such as Tai Chi or calligraphy, seemed to be more discrete. It was much easier to see progression in the series of language activities than the more culturallyfocused lessons. However, to provide a context for the language learning the teachers encouraged the young people to use newly acquired language in the activities. It was clear from the interviews that neither of the Hanban teachers planned sequences of activities specifically to focus on the development of social and personal skills. The exception to this were those lessons associated with meeting new people and being able to introduce oneself.

In reflecting upon his previous language teaching experience, the China Club 1 teacher considered that "learning a language is not easy, it is tough and boring, but if you want to learn fast, there is a lot of work to do, it is not interesting at all" (China Club 1 teacher, interview, June 23,2016$)$. He clearly took this into account when working with the young people to design activities that were demanding but not boring. He talks about ...the progression [in learning a language] is maybe slower...but every week we talk and they remember it. I know this is not a conventional way to teach at schools, not 
sticking to the syllabus, but because it is a club, have fun first. (China Club 1 teacher, interview, June 23, 2016).

He goes on to say:

You have to be very clear, very structured...so you're not just there and teaching some Chinese things, you have to think about what you are doing, why you are doing it, how you do it properly, what's the best way, really think of that. (China Club 1 teacher, interview, June 23, 2016).

This was echoed by the teacher of China Club 2 who explained that

there is no certain textbook so [you] need to just draw something and you want to teach what you think is most useful for them...I just look at some books and design my own class, use some interests that relate to their life so it can attract their attention. (China Club 2 teacher, interview, February 9, 2016).

These comments align with Marsh's (2012) suggestion that teachers must consider the planning of activities. China Club was designed to be recreational but consideration of the type and development of activities was still relevant and important. The two Hanban teachers paid attention to the participants" "progress and concerns" (Rhodes, 2004, p. 148) to ensure that they offered the kind of opportunities that an after-school setting allows.

\section{Active}

In their original report on promoting personal and social skills through after-school programmes, Durlak and Weissberg (2007) advocated "structured pursuits that...encourage them to contribute and take initiative, and contain challenging and engaging tasks that help 
them develop and apply new skills and personal talents" (p. 3). Given the young people's limited knowledge of China, Chinese culture and Mandarin language, all activities had the potential to prove challenging; what was important was engaging the young people. The Director of SCILT stated, "I always like to see the culture taught through the language; I don't like to see the two detached" (SCILT Director, interview, June 7, 2016). Therefore, the approaches taken to the activities were important to China Club's success as far as the SCILT Director was concerned.

The young people were rarely absent from China Club and this was partly because, as one of them said, "It's fun when you're not being forced to [participate]" (Participant 1, interview, June 22, 2016), with another adding that "In class you get forced to, in China Club you don't, because when someone tells you to do something, you just don't want to do it" (Participant 2, interview, June 22, 2016). It was clear that the young people chose to participate in the sessions. They were engaged and stimulated by the planned activities. There were opportunities for them to practise what they were learning and to receive feedback in order to improve and develop with "the cycle of practice and feedback continu[ing] until mastery is achieved" (Durlak et al., 2010, p. 296). Indeed, the notion of active learning was important in the context of China Club. In this context, active learning meant that participants were meaningfully engaged in contextualized learning that had relevance to their lives. This was especially the case when the young people were informed that they would be taken on a trip to China. This was more than the "hands-on form of learning" advocated by Durlak et al. (2010) “over exclusively didactic instruction” (p. 296). The experiential learning in China Club was richer and deeper than many after-school initiatives could hope for, especially given the expense and logistics involved in taking a group from their present setting to one at such a social, cultural and geographical remove. 
China Club 2 participants had not been given the opportunity to travel to China at the time of data collection. However, their activities were also designed to engage them actively and to ensure they were stimulated and interested. The Hanban teacher of this group noted that "they will have more interest about China and then if you acquire more of the Chinese culture...you want to learn more of the language" (China Club 2 teacher, interview, February 9, 2016). In relation to the activities that they were offered, one young person asserted that "Everything was actually quite good in its own way, like all the interactive games" (Participant 3, interview, June 22, 2016). Interactive activities were central to the success of China Club sessions and the observation logs indicated that the young people collaborated and worked enthusiastically. They sang songs together, cooked and ate together, played a treasure hunt game in the Chinese supermarket together and went on other trips, including to a Chinese restaurant and Edinburgh Zoo to see the pandas. Each January, the Confucius Institute and SCILT celebrate Robert Burns by holding a Burns' Night event. The China Club participants, the Hanban teachers, SCILT/CISS staff, members of the Chinese community and Scottish policy-makers and politicians were invited to attend. The young people from China Club led the social dancing, gave speeches in English and Mandarin and showcased their learning from China Club. Having these kinds of events allowed for greater engagement and a series of activities that are not always as possible for schools to deliver (Granger, 2008).

The teacher for China Club 2 was aware that the participants were a little tired because they came to the sessions immediately after the school day. To address this, and to provide further active learning opportunities, she deliberately slowed the pace a little and introduced the young people to Tai Chi and calligraphy, something she recognized might not necessarily be 
possible in the regular school context with the pressures upon teachers and pupils to perform. As mentioned earlier, the planned activities took into account the young people's interests, and the Hanban teacher saw this as important in ensuring their active engagement:

The first time I met the students, I asked them to write down their expectations and many of them liked music and sport, so I need to find more resources that relate to their interest, so I find the songs, even Jingle Bells, a very popular song, in Chinese. They seem very interested in [that] and they want to say 'ding, ding, dong' in Mandarin, so I think music or something that related to their interests will help. (China Club 2 teacher, interview, February 9, 2016).

Although working collaboratively was a key feature of much of the activity, the focus of the sessions was on learning Mandarin language and Chinese culture rather than developing social and personal skills per se.

\section{Focused}

In order for learning to take place, time and attention needs to be given to the initiative to ensure that it is focused on the development of skills (Durlak et al., 2010). The skills China Club set out to achieve were Mandarin language skills. This was paramount in the planning of activities, as evidenced in the interviews with the SCILT Director and the Hanban teachers. The observation logs also recorded the development of language skills and how these were built upon during the activities and also across the weeks. What was particularly interesting were the different approaches of the two Hanban teachers in this regard. The teacher for China Club 1 was less didactic or formal in teaching style than the teacher of 
China Club 2. Both prepared and planned activities, even the same activities, but they were conducted with a greater or lesser degree of formality.

The focus for the China Club 1 teacher was on teaching the young people something new that they may not have experienced before and that this should be an enjoyable experience. Fun was very much at the forefront of his plan for the Club, and this came from building positive relationships with the young people. This was evident when he said,

because this is an after-class club, so actually the teaching aspect is not that strong, so we spend a lot of time building relationship and have, generally speaking, just have fun with Chinese, what fun you can get from Chinese language and Chinese culture, so that's most things we do at the beginning. (China Club 1 teacher, interview, June $23,2016)$.

He went on to acknowledge that his approach was less traditional because there was no curriculum or syllabus. He said, "I know this is not a conventional way to teach at schools, not sticking to the syllabus, but because it is a club, have fun first". The China Club 2 teacher also spoke about the need for fun in the Club and how this was different from school, adding that the young people would be more informal by calling her by her first name, unlike the way they address their teacher. While she created activities that were intended to be fun, the focus was more structured than for the China Club 1 teacher. She had spoken with the SCILT Director about her high expectations and that she was keen that they learn as much language as possible. In her conversations with SCILT's Director and the China Club 1 teacher, she decided that 
maybe the most important thing is not to teach them the language, but you need to get them more interested about Chinese and Chinese culture, do some more fun like, do some very free experiments; it's not the thing, how much you have taught, it's how

much they have experienced. (China Club 2 teacher, interview, February 9, 2016).

This was a clear shift in the focus for the China Club 2 teacher, though she considered the China Club 1 group not to have learned as much Mandarin as she would have expected. This disparity between the two teachers suggests different priorities and foci. While both focused on experiential and fun learning experiences, they were differently orientated towards the language learning, with one adopting a more relaxed approach and the other holding what might be seen as more academic expectations. The nature of the 'clubness' perhaps needed to be more carefully or clearly explained to them, particularly because the teachers were from a different educational culture. The teachers' different cultural experiences were acknowledged by SCILT's Director who said that there had "been a misunderstanding about what an after-school club is" (SCILT Director, interview, June 7, 2016). For many Chinese young people, "an after-school club is where you go to study and prepare for exams" (SCILT Director, interview, June 7, 2016). She went on to explain that the two Hanban teachers came from different educational backgrounds in China, so professional development had been provided for them to support them in the Scottish context.

\section{Explicit}

The need to be explicit about the aims of an initiative is core in Durlak and Weissberg's (2007) original model. If an initiative is created to raise attainment or academic achievement, then there must be an explicit academic focus to the activities. Furthermore, the young people and staff involved in the initiative must be aware of these goals. It is not enough to set 
goals, targets or objectives in general terms; the intended learning has to be specific with clear learning outcomes stated (Durlak et al., 2010). The broad aim of China Club was to introduce young people to the Mandarin language and elements of Chinese culture. Running alongside this was an additional goal, as the Director of SCILT saw it, to provide "a mechanism [for] young people from more deprived areas for these kinds of opportunities, so we thought, if we do a China Club, that would be a way of developing that ladder for them" (SCILT Director, interview, June 7, 2016). It was through the China Club and the associated social events, presentations and showcasing events that the young people were introduced to people such as the Minister for Learning and Languages, the First Secretary for Scottish Affairs, and members of the Scottish China Education Network, for which they became ambassadors. The latter aim of raising the young people's aspirations was not shared explicitly with them in such stark terms, but they were told that University study was an option for them and that it was within their reach. With this aim in mind, SCILT and the Confucius Institute planned particular activities for the young people to learn from.

The specific aims of promoting foreign language learning, though, was more explicitly stated and planned for in the weekly sessions, with the Hanban teachers outlining to the young people what they would be learning and why. Thus, they made it evident how the learning built on previous activities or how it might be applied in context. While it was explicitly stated to the young people that it was hoped that their global awareness and cultural knowledge would be improved, the notion that their confidence would be enhanced, was not shared so openly. Observing the sessions, it was evident that the young people became more knowledgeable about aspects of Chinese culture. This knowledge and their global awareness became evident in the interviews and in their conference presentations. It was through the young people's self-reporting in their conference presentations and discussions about the visit 
to China, that it was clear that their confidence had also grown (Santoro et al., 2018). The planning of activities leading to increased confidence was perhaps less clear than the planning of activities that enhanced knowledge and awareness of language, culture and wider global awareness.

While Durlak and Weissberg (2007) advocate the need to share clear objectives in terms of skills development, as far as China Club was concerned, this remained within the realm of the language learning. No explicit objectives were shared concerning the development of personal and social skills, and this may have contributed to China Club's success. By focusing the young people's attention on language learning and learning about Chinese culture, they benefitted personally and socially. The personal and social growth they experienced developed naturally rather than through discrete and targeted skills-based activities.

\section{Discussions and conclusions: China Club-Safer than SAFE}

The aim of this study was to explore the effectiveness of China Club in meeting its goal of introducing young people from an area of particular social and economic disadvantage to Mandarin language and Chinese culture. Using Durlak and Weissberg's (2007) SAFE (sequenced, active, focused and explicit) framework as crucial in the successful development of young people's social and personal skills, we are able to offer recommendations for advancing initiatives such as China Club that are not designed specifically to raise academic attainment or to enhance young people's moral development. Leaving aside the range of after-school-initiatives where the findings from this study might have relevance, given that the concept of China Club is now part of a 'model' Confucius Institute initiative on a global 
scale, the scope for impact on the future design and implementation of other global China Clubs is significant. Indeed, there are lessons to be learned generally for schools, universities and their potential international partners when setting-up a new initiative. The importance of relationship-building should be acknowledged and nurtured from the outset.

Favouring the notion of social and personal growth as a more positive view of personal development over the idea of discrete skills, it is evident that China Club succeeds as a SAFE after-school initiative. However, the evidence from the study suggests China Club did more than this. We propose an extension of the Durlak and Weissberg model to include the fostering of relationships as central to the building of successful after-school initiatives. Durlak and Weissberg (2007) do not provide an ' $\mathrm{R}$ ' in their formula for the successful development of social and personal skills through after-school clubs, although Durlak et al.'s (2010) later work mentions the need for "social awareness and social relationships" (p. 295). Relationships were key to the success of China Club. While McDaniel and Yarbrough (2016) focused on mentoring relationships between those working with young people 'at risk' in after-school clubs, the feature of having "a positive and consistent adult" (p. 2) seems appropriate for all young people, and certainly seems to have supported the relationships between the Hanban teachers and the young people in China Club. Although the Hanban teachers were not intended to act as role models or mentors, they facilitated the positive relationships the young people established amongst themselves. Also, and significantly, they developed very strong relationships with the young people. This was particularly the case for the Hanban teacher from China Club 1 who accompanied the group to China. The school teachers who were committed to taking the young people to China Club each week also developed close relationships with them in ways that might not be possible in the normal school context. In school there are fewer opportunities to participate in activities and 
discussions of a more informal nature, and of the kind where positive interactions and relationships might develop (Rhodes, 2004). As Dell'Angello and Seaton (2016) suggest, a more informal environment where academic achievement is not the focus, allows relationships to evolve in a way that the normal classroom context does not. This, they say, is linked to the young people developing their identities which are, in turn, "influenced by experiences" (p. 125). The young people's sense of identity was certainly influenced by the experiences they had in writing to, and subsequently meeting, their Chinese peers and their families. This highlighted that that while there were some differences, they also had much in common. These interactions were new, exciting and vital in developing the young people. Wells (2009) highlights that young people gradually become more aware of being situated in society and the interconnections there are between themselves and other institutions and people in the wider social context.

The relationship with the China Club 1 teacher was particularly strong. He gave the young people choices over what they learned, followed their lead in terms of developing content, used humour effectively and had an approachable and friendly manner. This is exactly what Marsh (2012) suggests is necessary for successful relationships between teachers and young people. It may have been that because the teacher was young, he was able to connect well with the participants of China Club (Rhodes, 2004). However, he was not, as Rhodes suggests is necessary, from the same community. He simply had an approach to which the young people responded positively. Indeed, Rhodes (2004) goes on to suggest that "youth are likely to experience disappointment and sometimes even bereavement in response to the departure of beloved staff' (p. 157). This could be seen most clearly when China Club 1's teacher had to return to China after his year with SCILT. The young people wrote him a letter: 
You are the heart and soul of China Club and you will be extremely missed! You have been an amazing teacher, leader and friend to us all. You have really impacted us and we will never forget you. Thank you for every single thing you have ever done for us!! We all love you so much!! [Used with the group's consent]. (China Club 1 participants, personal letter, June 2016)

Rhodes (2004) also suggests that relationships between young people are positively influenced by their relationships with adults. At the beginning, several of the young people did not engage with, or even talk to one another outside of China Club because of entrenched generational conflict between their families. However, during the course of their involvement in China Club, they developed close relationships with each other. The role of the Hanban teachers in creating an environment of trust and cohesion cannot be over-estimated (see Santoro et al., 2018).

Positive relationships also led to the young people being confident to take risks and try new things. From the outset, China Club took the children away from the familiar, developing their resilience and risk-taking. They lacked self-consciousness in articulating the new Mandarin words and phrases they learned. They intoned, mimicking the teachers in a manner that was clearly foreign to their Scottish speech patterns. They volunteered to speak out in the sessions, to lead activities, to present at events and to speak to adults whose paths they would not otherwise have crossed. Individually, they volunteered to sing solo in Mandarin when in other contexts it could easily be imagined there would be a reluctance to sing in English. This is a feature that McDade (2005) suggests arises from mentors encouraging their 
protégés to move "beyond current comfort levels and abilities" (p. 767). In volunteering to try tongue-twisters in Mandarin there was the risk of appearing silly in front of peers, but the environment created was such that it promoted trust, respect and encouragement amongst peers. Hampden-Thompson and Galindo (2017) recognise the importance of the environment or climate in promoting this kind of positive experience. They note that leadership style is important, as is having clear expectations of the students while allowing for a range of outcomes from the young people. They also highlight the need to promote a caring atmosphere that engenders a community ethos.

It was clear that the young people and adults involved in the initiative contributed to the safe environment of China Club where young people were secure in experimenting with new things and, most notably, leaving home without their families to engage with a new culture and with new people with whom they were not familiar. The young people had a "sense of belonging” to China Club (Santoro et al., 2018). As Wells (2009) suggests, "by participating in activities with others to change their own conditions of existence, communities and their members can and do change themselves" (p. 47). In the case of China Club, the activities clearly effected change by building such strong relationships between the young people and their teachers, and among the young people themselves.

Earlier, we noted that SAFE can be split into two distinct elements: process and content. Process pertains to the sequential and active nature of the programme, while content relates to the focus and explicit nature of the learning. Relationships can be said to span process and content. The formation and nurturing of positive relationships may be a desired outcome, but these can only grow if they are taken into account in the design and implementation of the programme from the outset. 
We acknowledge that this research was limited in scope to one after-school programme in one area of Scotland. However, on the basis of our findings we suggest that an extension of Durlak and Weissberg's (2007) model is worthy of consideration. Initiatives that aim to develop the social and personal growth of young people should also consider how they facilitate effective relationships and what activities explicitly develop trust, risk-taking and collaboration. Many out-of-school activities emerge in response to a perceived need. Depending on the type of programme, there can sometimes be insufficient attention to planning. Indeed, to meet Hamilton's (2015) recommendation for collaboration between practitioners and university researchers, initiatives would do well to build assessment into the initiative's design, to extend the 'relationship' to include the researcher. They should also, as Hamilton and Hamilton (2015) propose, involve the participants in the design and research process too, thereby extending relationships even further. SAFER programmes, therefore, that attend to sequence, active, focused, explicit and relationships can potentially offer a framework to adults and professionals offering holistic out-of-school programmes.

\section{References}

Bennett, T. (2015). Examining levels of alignment between school and afterschool and associations with student academic achievement. The Journal of Expanded Learning Opportunities, 1(2), 4-22.

Bradshaw, C.P., Brown, J.S. and Hamilton, S.F. (2008) Bridging positive youth development and mental health services for youth with serious behaviour problems. Child \& Youth Care Forum 37(5-6), 209-226. 
Braun, V., and Clarke, V. (2013). Successful Qualitative Research: A Practical Guide Beginners. London: Sage.

Catalano, R.F., Berglund, M.L., Ryan, J.A.M., Lonczak, H.S. and Hawkins, J.D. (2004). Positive youth development in the United States: Research findings on evaluations of positive youth development programs. The ANNALS of the American Academy of Political and Social Science, 591(1), 98-124.

Cobbett, S. (2016). Reaching the hard to reach: Quantitative and qualitative evaluation of school-based arts therapies with young people with social, emotional and behavioural difficulties. Emotional and Behavioural Difficulties, 21(4), 403-415.

Cohen, L., Manion, L., \& Morrison, K. (2011). Research Methods in Education (7th ed.). London: Routledge.

Damon, W. (2004). What is positive youth development? The ANNALS of the American Academy of Political and Social Science, 591(1), 13-24.

Dell'Angello, T., \& Seaton, G. (2016). Students and teachers co-constructing identity. Journal of Urban Learning Teaching and Research, 12, 124-132.

Durlak, J.A., \& Weissberg, R.P. (2007). The Impact of After-School Programs that Promote Personal and Social Skills. Chicago, IL: Collaborative for Academic, Social, and Emotional Learning. 
Durlak, J.A., Weissberg, R.P., \& Pachan, M. (2010). A meta-analysis of after-school programs that seek to promote personal and social skills in children and adolescents. American Journal of Community Psychology, 45, 294-309.

Fredricks, J. A., \& Simpkins, S. D. (2013). Organized out-of-school activities and peer relationships: Theoretical perspectives and previous research. In J. A. Fredricks \& S. D. Simpkins (Eds.), Organized Out-of-School Activities: Settings for Peer Relationships New Directions for Child and Adolescent Development 140, 1-17.

Fusch, P. I., Fusch, G. E., \& Ness, L. R. (2017). How to conduct a mini-ethnographic case study: A guide for novice researchers. The Qualitative Report, 22(3), 923-941.

Granger, R.C. (2008). After-school programs and academics: Implications for policy, practice, and research. Social Policy Report, 22(2), 1-20.

Guest, G. MacQueen, K. \& Namey, E. (2011). Applied Thematic Analysis. Los Angeles, London: Sage.

Hamilton, M.A. \& Hamilton, S.F. (2015). Seeking social inventions to improve the transition to adulthood. Applied Developmental Science, 19(2), 87-107.

Hamilton, S.F. (2015). Linking research to the practice of youth development. Applied Developmental Science, 19(2), 57-59. 
Hamilton, S.F. (2014). On the 4-H study of positive youth development. Journal of Youth and Adolescence, 43(6), 1008-1011.

Hampden-Thompson, G. \& Galindo, C. (2017). School-family relationships, school satisfaction and the academic achievement of young people. Educational Review, 69(2), 248265.

Hammersley, M. (2006). Ethnography: Problems and prospects. Ethnography and Education, $1(1), 3-14$.

Hammersley, M. (2016). Reading Ethnographic Research. A Critical Guide (2nd ed.). London: Routledge.

Hirsch, B.J., Mekinda, M.A., \& Stawicki, J. (2010). More than attendance: the importance of after-school program quality. American Journal of Community Psychology, 45, 447-452.

Idsoe, E.M.C. (2016). The importance of social learning environment factors for affective well-being among students. Emotional and Behavioural Difficulties, 21(2), 155-166.

Jeffrey, B. (2008). Characteristic social settings as the basis for qualitative research in ethnography. In Geoffrey Walford (Ed.), How to do Educational Ethnography (pp. 115-139). London: The Tufnell Press.

Kohn, A. (1999). Punished by Rewards. The Trouble with Gold Stars, Incentive Plans, A's and Praise. Boston: Houghton Mifflin Company. 
McDade, S.A. (2005). Teacher-pupil: the changing relationships of mentors and protégés. Community College Journal of Research and Practice, 29(9-10), 759-781.

McDaniel, S., \& Yarbrough, A-M. (2016). A literature review of afterschool mentoring programs for children at risk. The Journal of At-risk Issues, 19(1), 1-9.

Marsh, H. (2012). Relationships for learning: Using pupil voice to define teacher-pupil relationships that enhance pupil engagement. Management in Education, 26(3) 161-163.

Patton, M. (2002). Qualitative Research and Evaluation Methods. California EU: Sage.

Pastor, A.M.R., \& Vásquez, O.A. (2011) Accountability of the informal: Challenges and new directions. Pedagogies: An International Journal, 6(3), 200-215.

Rhodes, J.E. (2004). The critical ingredient: Caring youth-staff relationships in after-school settings. New Directions for Youth Development, 101, 145-161.

Santoro, N., \& Smyth, G. (2010). Researching ethnic 'others': Conducting critical ethnographic research in Australia and Scotland. Intercultural Education, 21(6), 493-503.

Santoro, N., Cassidy, C. \& MacDonald, C. (2018). Building Bonding and Bridging Capital through the 'China Club'. International Journal of Adolescence and Youth, 23(3) 357-367. 
Scottish Government. (2012). Language learning in Scotland. A 1+2 approach. Scottish Government Languages Working Group. Report and recommendations. Edinburgh: Scottish Government.

Scottish Government. (2016). Scottish index of multiple deprivation index. Edinburgh:

Scottish Government. Retrieved from http://www.gov.scot/Topics/Statistics/SIMD

Simpkins, S., Riggs, N., Ngo, B., Vest Ettekal, A., \& Okamoto, D. (2017). Designing culturally responsive organized after-school activities. Journal of Adolescent Research, 32(1), $11-36$.

Wells, G. (2009). Schooling: the contested bridge between individual and society. Pedagogies: An International Journal, 5(1), 37-48.

White, K. L. (2009). Meztizaje and remembering in Afro-Mexican communities of the Costa Chica: Implications for archival education in Mexico. Archival Science, 9, 43-55. 